\title{
Are currently available biomarkers useful to discriminate CSU patients not controlled by low dose omalizumab maintenance therapy?
}

\author{
Allergology clinic, Clinica San Carlo, Paderno Dugnano, Milan, Italy
}

\section{KEY WORDS}

Chronic Urticaria; omalizumab;

biomarkers; IgE; D-dimer; therapy.

\author{
Corresponding author \\ Riccardo Asero \\ Allergology clinic \\ Clinica San Carlo \\ Via Ospedale 21 \\ 20037 Paderno Dugnano, Milan, Italy \\ E-mail: r.asero@libero.it
}

Doi

10.23822/EurAnnACI.1764-1489.139

\begin{abstract}
Summary
In patients with Chronic Spontaneous Urticaria (CSU), low dose omalizumab maintenance therapy is effective in about one half of complete, fast responders to the drug. Omalizumab $150 \mathrm{mg} /$ month was given as maintenance therapy to 21 patients with a history of severe CSU showing a complete $(U A S 7=0)$ response to the dose of $300 \mathrm{mg} /$ month. After 2 months of such regimen, patients were divided into controlled ( $n=14$; $U A S 7=0)$ and not controlled ( $n=7 ; U A S 7>10)$ and ESR, CRP, total IgE, and D-dimer were measured. The two groups did not differ in any of the biomarkers considered, nor in disease duration or in pre-treatment UAS7 score. The study confirms that it is possible to halve the dose of omalizumab without any loss of efficacy in a subgroup of patients with CSU but that none of the currently available biomarkers is able to predict which patients will lose disease control following omalizumab dose reduction.
\end{abstract}

\section{Introduction}

Omalizumab has become an essential part of the treatment of chronic spontaneous urticaria (CSU). In patients with severe disease that are unresponsive to antihistamine treatment at any dosage, omalizumab at a monthly dose of $300 \mathrm{mg}$ has been recommended as a safe and effective third line treatment (1). Omalizumab induces a rapid drop in UAS7 levels in about $70 \%$ of cases (the so-called fast responders) and a slower but equally good response over 3-4 months in further $15 \%$ of patients (slow responders); in contrast the remaining $15 \%$ seem refractory to the treatment (2).

Due to the current national Regulatory Agency (AIFA) rules, in Italy it is not possible to treat CSU patients with omalizumab for $>1$ year (11 administrations are licensed in total: a first course of 6 monthly $300 \mathrm{mg}$ doses followed by 5 further doses after a stop of no less than 2 months in case of relapse) with no possibility to resume the treatment in case of further relapses (3). This situation has prompted to look for alternative therapeutic strategies aiming to prolong the duration of the treatment as much as possible. Recently, this allergy center belonging to the GA2LEN-UCARE network proposed to pursue omalizumab treatment at the reduced dosage of $150 \mathrm{mg} /$ month as maintenance in patients who had shown a complete response to the drug (i.e., $\mathrm{UAS} 7=0$ ) at $300 \mathrm{mg} / \mathrm{month}$ (4). In that study, about one-half of the patients undergoing this regimen showed an ongoing excellent response, while in the other half the dose appeared to be insufficient and symptoms started again, albeit with lesser intensity than before the start of omalizumab treatment (4). In recent years several biomarkers have been detected for chronic spontaneous urticaria: some, like D-dimer plasma levels, are associated with a severe disease (5) that is unresponsive to antihistamine (6), while others such as total $\operatorname{IgE}$ are predictive of the response to omalizumab (7-9). In the present 
study these and other biomarkers were measured and compared in two subgroups of CSU patients responding differently to omalizumab $150 \mathrm{mg} / \mathrm{month}$ as maintenance treatment with the aim to investigate their prognostic value.

\section{Methods}

Twenty-one patients (M/F 7/14; mean age 49.4 years, median 51 years) with severe CSU (baseline UAS7 > 30) were enrolled. All of them had shown a rapid and complete $(\mathrm{UAS} 7=0)$ response to omalizumab at the dose of $300 \mathrm{mg} /$ month. After an informed written consent was obtained, the maintenance dosage of the drug during the second course of treatment was halved (i.e., $150 \mathrm{mg} / \mathrm{month}$ were given) in order to prolong the therapy period. ESR, CRP, plasma D-dimer, and total $\mathrm{IgE}$ were measured after two months at the reduced dose regimen. Based on their clinical response, patients were classified as fully con- trolled (i.e., persistence of UAS7 $=0$ ) or insufficiently controlled (appearance of wheals with or without angioedema; i.e., UAS7 $>10$ ). Disease duration in months and thyroid autoimmunity were considered as well.

Clinical results compared by Chi-Square Test with Yates' correction. Probability values less than 5\% were considered statistically significant.

\section{Results}

Table I shows the clinical findings in the study population. Fourteen patients continued to show a complete control of the disease despite the dose reduction of omalizumab, whereas 7 showed a relapse of the disease whose severity did nonetheless never reach the levels preceding the start of omalizumab treatment. The two subgroups did not show any difference in any of the analyzed parameters. A marked increase in total $\operatorname{IgE}$ from

Table I - Clinical features of the study population.

Omalizumab

\begin{tabular}{|c|c|c|c|c|c|c|c|c|c|c|c|c|c|}
\hline Patient & Sex & Age & DD & ESR & CRP & Atopy & Thyroid & D-dimer & $\operatorname{IgE}$ & ESR & CRP & D-dimer & IgE \\
\hline $1 \mathrm{~A}$ & $\mathrm{M}$ & 50 & 24 & $\mathrm{Neg}$ & $\mathrm{Neg}$ & $\mathrm{Neg}$ & $\mathrm{Neg}$ & 312 & nd & $\mathrm{Neg}$ & neg & 170 & 459 \\
\hline $2 \mathrm{~A}$ & $\mathrm{M}$ & 59 & 60 & $\mathrm{Neg}$ & Pos & POS & $\mathrm{Neg}$ & 588 & 251 & $\mathrm{Neg}$ & Pos & 746 & 438 \\
\hline $3 \mathrm{~A}$ & $\mathrm{~F}$ & 37 & 88 & $\mathrm{Neg}$ & $\mathrm{Neg}$ & POS & $\mathrm{Neg}$ & 3764 & nd & $\mathrm{Neg}$ & neg & 365 & 256 \\
\hline $4 \mathrm{~A}$ & $\mathrm{~F}$ & 47 & 36 & $\mathrm{Neg}$ & $\mathrm{Neg}$ & $\mathrm{Neg}$ & $\mathrm{Neg}$ & 450 & nd & $\mathrm{Neg}$ & neg & 250 & 97 \\
\hline $5 \mathrm{~A}$ & $\mathrm{~F}$ & 22 & 48 & $\mathrm{Neg}$ & $\mathrm{Neg}$ & POS & POS & 443 & 372 & POS & neg & 230 & 2251 \\
\hline $6 \mathrm{~A}$ & $\mathrm{~F}$ & 47 & 18 & Pos & Pos & $\mathrm{Neg}$ & POS & 1200 & nd & $\mathrm{Neg}$ & neg & 437 & 62 \\
\hline $7 \mathrm{~A}$ & $\mathrm{M}$ & 65 & 18 & $\mathrm{Neg}$ & Pos & $\mathrm{Neg}$ & $\mathrm{Neg}$ & 1815 & nd & $\mathrm{Neg}$ & Pos & 541 & 523 \\
\hline $1 \mathrm{~B}$ & $\mathrm{M}$ & 60 & 200 & $\mathrm{Neg}$ & $\mathrm{Neg}$ & $\mathrm{Neg}$ & POS & 6063 & 256 & $\mathrm{Neg}$ & $\mathrm{Neg}$ & 350 & 565 \\
\hline $2 \mathrm{~B}$ & $\mathrm{~F}$ & 58 & 3 & $\mathrm{Neg}$ & $\mathrm{Neg}$ & $\mathrm{Neg}$ & $\mathrm{Neg}$ & 315 & 490 & $\mathrm{Neg}$ & $\mathrm{Neg}$ & 320 & 876 \\
\hline $3 \mathrm{~B}$ & $\mathrm{~F}$ & 28 & 6 & $\mathrm{Neg}$ & $\mathrm{Neg}$ & POS & $\mathrm{Neg}$ & 514 & 18 & $\mathrm{Neg}$ & $\mathrm{Neg}$ & 294 & 52 \\
\hline $4 \mathrm{~B}$ & $\mathrm{~F}$ & 29 & 16 & $\mathrm{Neg}$ & $\mathrm{Neg}$ & $\mathrm{Neg}$ & $\mathrm{Neg}$ & 263 & 181 & $\mathrm{Neg}$ & $\mathrm{Neg}$ & 251 & 263 \\
\hline $5 \mathrm{~B}$ & $\mathrm{M}$ & 67 & 180 & $\mathrm{Neg}$ & neg & $\mathrm{Neg}$ & $\mathrm{Neg}$ & 622 & 51 & $\mathrm{Neg}$ & $\mathrm{Neg}$ & 380 & 136 \\
\hline $6 \mathrm{~B}$ & $\mathrm{~F}$ & 66 & 36 & $\mathrm{Neg}$ & $\mathrm{Neg}$ & $\mathrm{Neg}$ & $\mathrm{Neg}$ & 985 & 20 & POS & $\mathrm{Neg}$ & 392 & 133 \\
\hline $7 \mathrm{~B}$ & $\mathrm{~F}$ & 35 & 150 & $\mathrm{Neg}$ & $\mathrm{Neg}$ & POS & $\mathrm{Neg}$ & 1500 & nd & $\mathrm{Neg}$ & $\mathrm{Neg}$ & 181 & 422 \\
\hline $8 \mathrm{~B}$ & $\mathrm{~F}$ & 39 & 4 & $\mathrm{Neg}$ & $\mathrm{Neg}$ & $\mathrm{Neg}$ & $\mathrm{Neg}$ & 397 & 308 & $\mathrm{Neg}$ & $\mathrm{Neg}$ & 340 & 583 \\
\hline $9 \mathrm{~B}$ & $\mathrm{M}$ & 69 & 7 & $\mathrm{Neg}$ & $\mathrm{Neg}$ & $\mathrm{Neg}$ & $\mathrm{Neg}$ & 402 & 148 & $\mathrm{Neg}$ & $\mathrm{Neg}$ & 200 & 391 \\
\hline $10 \mathrm{~B}$ & $\mathrm{~F}$ & 70 & 2 & $\mathrm{Neg}$ & $\mathrm{Neg}$ & $\mathrm{Neg}$ & $\mathrm{Neg}$ & 370 & 68 & Pos & $\mathrm{Neg}$ & 310 & 169 \\
\hline 11B & $\mathrm{F}$ & 31 & 48 & $\mathrm{Neg}$ & $\mathrm{Neg}$ & $\mathrm{Neg}$ & $\mathrm{Neg}$ & 446 & 76 & $\mathrm{Neg}$ & $\mathrm{Neg}$ & 360 & 237 \\
\hline $12 \mathrm{~B}$ & $M$ & 55 & 2 & Neg & $\mathrm{Neg}$ & POS & $\mathrm{Neg}$ & 502 & 392 & $\mathrm{Neg}$ & $\mathrm{Neg}$ & 189 & 951 \\
\hline $13 \mathrm{~B}$ & $\mathrm{~F}$ & 53 & 24 & $\mathrm{Neg}$ & Pos & POS & $\mathrm{Neg}$ & 2520 & nd & POS & pos & 520 & 322 \\
\hline 14B & $F$ & 51 & 49 & $\mathrm{Neg}$ & $\mathrm{Neg}$ & $\mathrm{Neg}$ & POS & 1158 & 24 & $\mathrm{Neg}$ & $\mathrm{Neg}$ & 291 & 134 \\
\hline
\end{tabular}

Legend: Patients: A not controlled by Omalizumab $150 \mathrm{mg} / \mathrm{month}$; B: well controlled by Omalizumab $150 \mathrm{mg} / \mathrm{month}$.

DD: disease duration (months); D-dimer levels are expressed as ng/ml; Total IgE: cut-off $100 \mathrm{UI} / \mathrm{ml}$.

POS: positive; Neg: negative; nd: not done. 
baseline levels was recorded in all patients; in contrast, D-dimer plasma levels had dropped to normal levels in 19/21 patients and to borderline levels in the remaining two. ESR and CRP were normal in virtually all cases. The prevalence of thyroid autoimmunity was similar in the two groups as was the disease duration and the severity of the disease at the start of omalizumab treatment. Full blood counts showed a reduced number of basophils (basopenia) in all cases before the beginning of omalizumab treatment (first course) but were not controlled again after the start of the treatment.

\section{Discussion}

Previous studies showed that D-dimer plasma levels are elevated in a proportion of patients with chronic spontaneous urticaria and decrease dramatically according to the clinical response to treatment (10). This study fully confirmed this finding, as in all patients showing very elevated D-dimer plasma levels before starting anti-IgE treatment D-dimer dropped within the normal range during the treatment. Theoretically it was conceivable that in some patients the loss of clinical control was associated with an increase in D-dimer levels (10) but this event did not occur, possibly because these patients were in effect omalizumab responders (albeit undertreated) and did not develop any resistance to the drug (11).

Total IgE baseline levels are frequently slightly elevated in patients with CSU, especially in those who respond promptly to omalizumab (7-9). Omalizumab administration eventually leads to an increase in total IgE levels while reducing their free fraction due to the prolongation of their half-life, and such

\section{References}

1. Zuberbier T, Aberer W, Asero R, et al. The EAACI/GA²LEN/ $\mathrm{EDF} / \mathrm{WAO}$ guideline for the definition, classification, diagnosis and management of urticaria. Allergy 2018;73:1393-1414.

2. Zhao ZT, Ji CM, Yu WJ, Meng L, Hawro T, Wei JF, Maurer M. Omalizumab for the treatment of chronic spontaneous urticaria: A meta-analysis of randomized clinical trials. J Allergy Clin Immunol 2016;137:1742-1750.

3. Asero R, Canonica GW, Cristaudo A, et al. Critical appraisal of the unmet needs in the treatment of chronic spontaneous urticaria with omalizumab: an Italian perspective. Curr Opin Allergy Clin Immunol 2017;17:453-459.

4. Asero R. Efficacy of omalizumab $150 \mathrm{mg} /$ month as a maintenance dose in patients with severe chronic spontaneous urticaria showing a prompt and complete response to the drug. Allergy 2018;73:2242-2244.

5. Asero R, Tedeschi A, Riboldi P, Griffini S, Bonanni E, Cugno M. Severe chronic urticaria is associated with elevated plasma levels of D-dimer. Allergy 2008;63:176-80.

6. Asero R. D-dimer: a biomarker for antihistamine-resistant chronic urticaria. J Allergy Clin Immunol 2013;132:983-6.

7. Ertas R, Ozyurt K, Atasoy M, Hawro T, Maurer M. The clinical response to omalizumab in chronic spontaneous urticaria patients increase may last for more than one year after stopping the treatment (12). Since fast omalizumab responders represented the whole population enrolled in the study it is not surprising that total IgE levels were frequently elevated before omalizum$a b$ treatment and increased in all cases under anti-IgE therapy. Theoretically, it could be hypothesized that patients whose disease was no longer controlled by $150 \mathrm{mg} / \mathrm{month}$ of omalizumab showed higher mean total IgE levels than persistent full responders but, again, this was not the case, possibly because total $\operatorname{IgE}$ that are measured in serum reflect only partially the IgE fraction bound to effector cells. Finally, that blood basophils count is inversely related with disease activity is well known (13). This was observed also here, as all patients showed basopenia when omalizumab treatment was started. Unfortunately, since circulating basophils numbers were not re-measured during the treatment with anti-IgE, whether patients not responding or responding to $150 \mathrm{mg}$ of omalizumab as maintenance therapy showed differenced in basophils counts remains unclear.

Thus, the present study confirms that it is possible to halve the dose of omalizumab without any loss of efficacy in a large subgroup of CSU patients showing an excellent response to the full dose of the drug but also shows that none of the currently available biomarkers of efficacy or severity is able to predict which patients will lose the control of the disease following omalizum$\mathrm{ab}$ dose reduction.

\section{Conflict of interests}

The author declares that he has no conflict of interests.

is linked to and predicted by IgE levels and their change. Allergy 2018;73:705-712.

8. Straesser MD, Oliver E, Palacios T, et al. Serum IgE as an immunological marker to predict response to omalizumab treatment in symptomatic chronic urticaria. J Allergy Clin Immunol Pract 2018;6:1386-1388.

9. Weller K, Ohanyan T, Hawro T, et al. Total IgE levels are linked to the response of chronic spontaneous urticaria patients to omalizumab. Allergy 2018;73:2406-2408.

10. Asero R, Marzano AV, Ferrucci S, Cugno M. D-Dimer Plasma Levels Parallel the Clinical Response to Omalizumab in Patients with Severe Chronic Spontaneous Urticaria. Int Arch Allergy Immunol 2017;172:40-44

11. Asero R. Serial D-dimer plasma levels in a patient with chronic spontaneous urticaria developing resistance to omalizumab. Clin Exp Dermatol 2017;42:667-669.

12. Eckl-Dorna J. Omalizumab's impact on total and allergen-specific $\mathrm{IgE}$ levels: a polyclonal story. Int Arch Allergy Immunol 2016;169:69-70.

13. Saini SS. Basophil responsiveness in chronic urticaria. Curr Allergy Asthma Rep 2009;9:286-90. 